\title{
IMPLICACIONES DE LA NEUROCIENCIA. PSICOFÁRMACOS E IDENTIDAD: ENTRE LA CULTURA Y LA BIOLOGÍA
}

\author{
LYDIA FEITO GRANDE \\ Universidad Complutense, Madrid
}

\begin{abstract}
RESUMEN: Los avances neurocientíficos abren la posibilidad de modificar las capacidades del ser humano, con afán de mejorarlo. Un ejemplo de estos cambios se encuentra en los neurofármacos. Alterar la memoria, la atención o el ánimo pueden suponer un cambio de identidad personal. Se analiza esta cuestión de la identidad y lo que pueda suponer de modificación de una naturaleza humana, lo que lleva a replantear el debate entre naturaleza y cultura, también desde la neurociencia actual. Se concluye que el dinamismo de la identidad narrativa humana es el resultado de esa interacción.
\end{abstract}

PALABRAS CLAVE: neurociencia, identidad personal, neuroética, cultura, naturaleza.

\section{Implications of neuroscience Psychoactive drugs and identity: between history and culture}

ABSTRACT: Neuroscientifical advances open the possibility to modify capacities in human beings, aimed to enhance them. An example is neurodrugs. Altering memory, attention or mood can make a difference in personal identity. This question about identity is analyzed and its implications on modification of human nature. This raises again the nature/culture debate, also from the contemporary neuroscience. The conclusion is that dynamism in human narrative identity is the result of an interaction between nature and culture.

KEY WORDS: neuroscience, personal identity, neuroethics, culture, nature.

\section{Introducción. Problemas éticos suscitados por las neurociencias}

Durante las últimas décadas hemos asistido a un crecimiento vertiginoso de los estudios neurocientíficos que tratan de explicar fenómenos antes aparentemente misteriosos. Así, muchos procesos cuya comprensión era difícil, ahora encuentran una causa en el cerebro, y se evidencian mecanismos subyacentes de las operaciones mentales y de los comportamientos. En buena medida, experimentamos algunas de estas explicaciones como "pérdidas», porque lo que antes estaba sometido a un halo de misterio y magia, ahora parece poder ser reducido a fenómenos biofísicos, bastante prosaicos. Estaríamos así «destejiendo el arco iris» como decía aquel poema de J. Keats, quien consideraba que Newton había destruido la poesía del arco iris al reducirlo al prisma de colores por la descomposición de la luz.

Una crítica frecuente a este tipo de planteamientos es el reduccionismo del que hacen gala, en su entusiasta defensa de una explicación neurológica o genética para todo lo que acontece en el ser humano, pareciendo que incluso elementos tan sobresalientes para nuestra humanidad, como la libertad o el amor, son ahora explicables, exclusivamente, como procesos bioquímicos o biofisiológicos.

Sin embargo, la neurociencia no sólo encuentra explicaciones biológicas para los comportamientos sino que, cada vez más, observa que las influencias ambientales, culturales, pueden modificar el cerebro y, por tanto, que en el clásico debate entre naturaleza y cultura, ambos factores pueden ser relevantes. 
Estos aspectos son esenciales para abordar los problemas suscitados por la neurociencia y sus implicaciones.

Muchos de los problemas éticos suscitados por la neurociencia son similares a otros problemas bioéticos que han ido surgiendo previamente en la biomedicina, como la seguridad de los métodos de investigación y tratamiento, la limitación en las expectativas generadas por las nuevas terapias, la disponibilidad de pruebas predictivas para enfermedades futuras que no tienen curación (como el Alzheimer o la enfermedad de Huntington), o la amenaza a la confidencialidad y la privacidad.

Sin embargo, hay otras cuestiones neuroéticas que son específicas y únicas de la neurociencia, por razón de la peculiar materia de la que trata este campo. El cerebro, como órgano de la mente, es el lugar en donde reside el sentido de nuestra identidad. Por ello, las intervenciones en el cerebro tienen implicaciones éticas distintas a las realizadas en otros órganos. Además, el conocimiento creciente que vamos adquiriendo sobre las relaciones entre mente y cerebro afecta a las definiciones de capacidad, salud o enfermedad mental, e incluso de muerte. Igualmente, en la medida en que cambie nuestra comprensión de los mecanismos que subyacen a los comportamientos, pueden verse afectados conceptos que no sólo tienen implicaciones éticas sino también legales, como la responsabilidad.

La mayor parte de los problemas éticos en la neurociencia resultan de dos desarrollos: (1) la capacidad de visualizar la función cerebral en los seres humanos vivos, con una resolución espacial y temporal suficiente como para captar fluctuaciones de actividad con significación. Esto está llevando a la posibilidad de explicar procesos cognitivos o comportamientos en función de las activaciones cerebrales, en ocasiones con un planteamiento excesivamente simplificador. Y (2) la capacidad de alterar la actividad cerebral por medios físicos o químicos, de modo selectivo, para inducir cambios funcionales específicos. Este segundo aspecto conduce a las posibilidades de mejora, esto es, de modificación de rasgos y capacidades, de modo permanente o temporal, que puede suponer una alteración de nuestra identidad y, quizá, de nuestra misma naturaleza humana. En lo que sigue, nos centraremos en esta cuestión.

\section{INTERVENCIONES CEREBRALES POR MEDIOS QUÍMICOS: MEJORA FARMACOLÓGICA}

Entre las muchas posibilidades de modificación de la actividad cerebral, se encuentran las técnicas de mejora neurocognitiva, esto es, la utilización de drogas y otras intervenciones no farmacológicas en el cerebro (psicocirugía, estimulación cerebral profunda, etc.) para mejorar a las personas en cuanto a sus capacidades mentales.

En muchos casos, estas nuevas posibilidades generan preocupación e interrogantes éticos. Se discute sobre los objetivos de las transformaciones, sobre los fines que persiguen. Pero también, obviamente, sobre los medios para lograrlos. Por ejemplo, es muy posible encontrar un acuerdo mayoritario en considerar que tener más memoria es algo mejor que conformarse con la capacidad actual y sus olvidos. Sin embargo, no hay tal acuerdo en la utilización de neurofármacos o chips integrados en el cerebro para lograrlo.

La novedad del planteamiento actual reside en la disponibilidad de una serie de tecnologías que abren espacios de mejora antes inimaginables. En algunos casos se trata de cambios realmente espectaculares, pero en otros, los que probablemente se van incorporando con más facilidad y rapidez en la sociedad, son simplemente aplicaciones 
nuevas de cosas conocidas, o nuevos desarrollos que van más allá de lo inicialmente buscado.

Así, fármacos que se habían desarrollado originalmente para tratar enfermedades como la narcolepsia o el déficit de atención con hiperactividad (TDAH) - por tanto, con un objetivo claramente terapéutico-, se utilizan ahora, fuera de la indicación inicial, para incrementar la memoria, el período de atención, o la capacidad para concentrarse en tareas cognitivas. Incluso, algunos de estos fármacos pueden mejorar las funciones ejecutivas, o la capacidad de resolver problemas, lo cual, sin duda es algo atrayente para multitud de personas. De hecho, existen estudios que muestran cómo uno de estos medicamentos para el TDAH, el Ritalin (metilfenidato), es el más utilizado, para rendir mejor en los exámenes, entre los estudiantes universitarios (dependiendo de los estudios, se estima entre un 10\% en Europa, y casi un 20\% en Estados Unidos).

Muchas personas valoran este tipo de usos de los fármacos, por una parte, como algo preocupante que tiene que ver con el problema, más global, del uso de las drogas, y, por otra parte, como una forma de engaño o falsificación, pues los logros obtenidos de este modo no serían fruto del esfuerzo personal, sino de una ayuda química.

Buena parte de los problemas éticos generados por esta posibilidad son similares a los que se han planteado ante otras posibilidades de mejoras físicas, como el dopaje en el deporte para lograr marcas o ganar competiciones, o la utilización de la hormona del crecimiento para mejorar la altura de los niños. Pero también hay algunos problemas éticos nuevos que surgen en relación a la mejora cerebral, pues estos cambios afectan al modo de pensar y sentir de la gente, lo que genera nuevas preocupaciones en relación a lo que se ha dado en llamar «libertad cognitiva».

La libertad cognitiva es la libertad de tener el control soberano sobre la propia conciencia. Es una extensión de los conceptos de libertad de pensamiento y autoposesión. $\mathrm{El}$ «Centro para la libertad cognitiva y la ética» — un centro americano, sin ánimo de lucro, fundado y dirigido por el neuroeticista Wrye Sententia y el teórico legal Richard Glen Boire-, define la libertad cognitiva como «el derecho de cada individuo a pensar independiente y autónomamente, para utilizar todo el espectro de su pensamiento, e implicarse en múltiples modos de pensamiento.»

Un individuo que disfruta de libertad cognitiva es libre para alterar el estado de su conciencia utilizando cualquier método de su elección, incluyendo elementos tan variados como la medicación, el yoga, las drogas psicoactivas, la oración, etc. Tal individuo nunca sería forzado a cambiar su conciencia contra su voluntad. Así, por ejemplo, un niño que es obligado a consumir Ritalin como prerrequisito para ir a la escuela pública, no disfruta de libertad cognitiva, y tampoco un individuo que fuera forzado a tomar anti-psicóticos para poder ir a juicio.

El papel creciente de la psicofarmacología en la vida cotidiana suscita también problemas éticos, como la influencia del mercado farmacéutico en nuestras concepciones de la salud mental y la normalidad, y el sentido crecientemente maleable de identidad personal que resulta de lo que Peter Kramer llamó "psicofarmacología cosmética», esto es, el uso de drogas para mejorar la cognición de los individuos normales y sanos.

La mejora de los estados de ánimo es, probablemente, uno de los aspectos que más dudas suscitan, en la medida en que parecen no sólo propiciar un cambio adaptativo, posibilitando que ciertas capacidades puedan desarrollarse mejor, sino que parecen influir y modificar aspectos que tienen que ver con la identidad de los individuos.

El ejemplo más conocido es el uso de los ISRS (inhibidores selectivos de la recaptación de serotonina), como el Prozac (fluoxetina), una clase de compuestos típicamente 
usados en el tratamiento de cuadros depresivos, trastornos de ansiedad, y algunos trastornos de personalidad. Son los antidepresivos más prescritos en muchos países.

Algunos casos relacionados con el Prozac, indicaban que los pacientes parecían «mejor que bien», y los autores lanzaron la hipótesis de que este efecto se podría observar también en individuos sin ningún trastorno psiquiátrico. A partir de ese momento, el uso de la llamada "píldora de la felicidad» se ha extendido de un modo vertiginoso. Sin embargo, sigue siendo controvertido este uso de un fármaco en situaciones no patológicas, que refleja de modo visible cómo nuestras sociedades desarrolladas amplían progresivamente sus demandas de salud hacia la búsqueda incesante del bienestar. Por otro lado, es también objeto de debate la veracidad de las promesas y expectativas generadas por estos fármacos y, en general, la idoneidad del uso cosmético de estos antidepresivos. Los opositores a la farmacología cosmética creen que el uso de estos fármacos es la manifestación de un consumismo propiciado por el mercado y, por tanto, sometido a intereses económicos. Sin embargo, sus defensores, como A. Caplan, consideran que los individuos tienen derecho a determinar si quieren usar esos fármacos o no, y por tanto es un ejercicio de la autonomía individual.

La pregunta abierta es si estas técnicas de mejora son adecuadas.

Por una parte, como apunta Caplan, parece que los individuos deberían tener la posibilidad de elegir cómo quieren vivir y lograr sus objetivos. Así, al disponer de técnicas que puedan favorecer el desarrollo de las capacidades, sería una cuestión de libertad elegir su uso o no. Este es el planteamiento de Julian Savulescu quien, partiendo de la constatación de que todos buscamos mejorarnos, esto es, ser más inteligentes, estar más sanos, tener más fuerza, estar más atractivos, etc., afirma que, en el caso de que dispusiéramos de una técnica biomédica que nos permitiera hacer mejoras, no sólo no sería inmoral utilizarla, sino que sería obligatorio.

Savulescu considera que si pudiéramos hacer que nuestros hijos tuvieran más posibilidades, desde el punto de vista biológico, sería legítimo ofrecérselas. No habría razón para aceptar las mejoras ambientales y no las biológicas, éstas también deben ser utilizadas, pues pueden ser igual de determinantes y/o posibilitadoras. En buena medida, su argumentación trata de buscar la coherencia: si aceptamos tratar enfermedades, debemos aceptar la mejora, pues hay una difícil distinción entre enfermedad o discapacidad — que justifica la terapia—y malestar — que abre paso a la mejora—, teniendo en cuenta la pluralidad en la definición de salud.

Más aún, Savulescu formula un «Principio de beneficencia procreativa» según el cual las parejas, o personas individuales, deben seleccionar al niño, de entre los hijos posibles que podrían tener, del que se pueda esperar que va a tener la mejor vida, o al menos una vida mejor que los otros, basándose en la información relevante disponible.

La «mejor vida» se define como aquella que pueda disfrutar de mayor bienestar. Y la legitimidad de su persecución radica en el hecho de que los padres siempre buscan ese objetivo, aunque por medios ambientales (por ejemplo, eligiendo el momento de tener a su hijo cuando su situación económica sea favorable). La novedad está en la aceptación de medios biológicos para lograrlo.

Por ello Savulescu considera que la selección de genes, patológicos o no, la selección de sexo, la selección de embriones, o la mejora son una obligación moral. No se puede, se debe seleccionar y buscar la mejora. No hacerlo, disponiendo de los medios, sería inmoral.

Evidentemente, esto implica la posibilidad de que las mejoras hagan, de dichos individuos o de sus descendientes, posthumanos. La razón fundamental que justifica esta postura es que, el hecho de que algunas personas pudieran hacer malas elecciones, 
dando lugar a un subhumano, más que a un posthumano (como pronostican las antiutopías), no es razón suficiente para rescindir el derecho a elegir de las personas. No al menos en una democracia liberal. De ahí que, más que medidas restrictivas, sea necesario promover contramedidas adecuadas como la educación, la persuasión, y una reforma social y cultural.

Sin embargo, por otro lado, las modificaciones biológicas introducen de modo muy palpable una cuestión importante: el cambio de la identidad de los individuos. Conviene tener en cuenta que esto no es exclusivo de las intervenciones farmacológicas, ni de las técnicas de mejora biológica. También los cambios educativos, culturales, ambientales, son determinantes para la vida de los individuos, los configuran y les dotan de unas capacidades y posibilidades, a costa de perder otras. Y sus cambios pueden ser tan irreversibles e impuestos como los biológicos. No obstante, permanece una convicción, quizá irracional, de que sólo —o mayormente- lo biológico es lo que puede cambiar «nuestra naturaleza»y, por tanto, puede hacernos perder nuestra misma humanidad.

A ello cabe añadir que nuestra cultura ve con buenos ojos el esfuerzo, la constancia, el empeño en ser mejor, como virtudes que muestran un afán de superación y un cultivo y desarrollo de nuestras capacidades. Pero siempre por medios ambientales y culturales. De hecho, en relación al mencionado fármaco Prozac, se hizo famoso hace años un libro titulado Más Platón y menos Prozac en el que Lou Marinoff se planteaba la necesidad de no confiar tanto en los fármacos, y dedicar más atención al cultivo de una reflexión serena sobre uno mismo, de un análisis racional de las propias emociones y modo de afrontar los conflictos y, en definitiva, de promover y favorecer un crecimiento y maduración personal, antes de abandonarse a las bondades de un fármaco en el que depositamos todas nuestras esperanzas de recuperación y, quizá, de logro de la felicidad.

Pero, ¿por qué confiamos tanto en estos cambios culturales, y sospechamos de las modificaciones biológicas? ¿Por qué concedemos tanta importancia a nuestras capacidades intelectuales y afectivas, y sin embargo, creemos que es mejor cultivarlas con esfuerzo en lugar de mejorarlas desde su sustrato material? ¿Por qué pensamos que podríamos perder nuestra humanidad, nuestra identidad, por modificar nuestra condición biológica? ¿Por qué nos genera tanta preocupación la posibilidad de «no ser nosotros mismos» si utilizamos psicofármacos - $\mathrm{u}$ otras técnicas - para incrementar nuestras capacidades? ¿Por qué un "yo mejorado» es menos yo que el «natural»? ¿Existe realmente un «yo natural» no modificado, teniendo en cuenta que somos realidades dinámicas en permanente cambio, influidos por factores de muy diversa índole? ¿Un yo que pudiera desarrollar al máximo sus capacidades, actualizar sus potencialidades, no sería «más yo»?

\section{La CUESTIÓN DE LA IDENTIDAD}

David DeGrazia distingue entre dos sentidos diferentes de identidad: la identidad numérica y la identidad narrativa. Algunas tradiciones filosóficas se han centrado en la identidad numérica, entendida como la relación que tiene una entidad consigo misma, como siendo una y la misma a lo largo del tiempo. Los cambios que se van produciendo a lo largo de los años son accidentales, de modo que la persona puede asumirlos, aunque sean enormes, sin perder la noción de que dichos cambios le ocurren a él o ella. Esta continuidad psicológica, y también biológica — pues, según las diferentes teorías, se enfatiza una u otra-, incorpora también una concepción de un sustrato esencial de la persona, que sirve de soporte para sus características. Los debates se centran en cuál es ese elemento subyacente, una entidad autoconsciente, o un organismo vivo. 
La identidad narrativa, por su parte, se refiere a la autoconcepción que tiene el individuo de sí mismo: sus valores, su biografía, sus experiencias vividas, los roles que lo definen, etc. De modo que lo importante está en el relato que puede hacer, que en algunos momentos puede encontrar un punto de inflexión, una crisis de identidad, que obliga a su protagonista a reconfigurar la lógica de esa autobiografía.

Esta interesante distinción había sido ya propuesta, de modo más profundo y elaborado, por P. Ricoeur. Los conceptos que maneja el pensador francés son el de identidad como «mismidad» y como «ipseidad», lo que le sirve para denunciar no sólo su posible confusión, sino el fracaso de cualquier reflexión sobre la identidad personal que ignore la dimensión narrativa.

La mismidad hace referencia a la permanencia en el tiempo —equivaldría a lo que DeGrazia denomina identidad numérica-, tiene que ver con el hecho de que algo sea una sola y la misma cosa, lo cual supone unicidad y también identificación o reconocimiento de lo mismo consigo mismo. Pero puede ir más allá, introduciendo una dimensión más cualitativa, que toma en consideración el factor tiempo. En este caso se busca una continuidad, por similitud, entre los estadios de desarrollo de un individuo, y por tanto, una permanencia en el tiempo.

Evidentemente, este planteamiento conduce a la pregunta sobre la existencia de un sustrato, que sea el soporte de esa permanencia y continuidad. En este punto es donde Ricoeur introduce el concepto de ipseidad, al afirmar que la constitución de la identidad supone la mismidad pero no se agota en ella. Dicho de otro modo, la ipseidad «recubre» la mismidad, como una segunda naturaleza que, sin embargo, es lo esencial, es lo que determina el yo, en el que se reconoce una persona, el rasgo distintivo de su identidad. Por eso, para pensar la persona y su identidad es imprescindible recurrir a esta identidad narrativa, porque es la que puede decirnos «quién» es ese sujeto humano. No es sólo un "qué», es una identidad, un conjunto de posibilidades que se han configurado a lo largo del tiempo, en el movimiento de una narración, generando una historia.

El tema, obvia decirlo, es complejo y muy interesante, pero excede los objetivos de este texto. Para lo que nos ocupa, desde el punto de vista de la posible modificación de la identidad, los dos tipos suponen aproximaciones diferentes. La preocupación por los criterios que determinan si alguien sigue siendo el mismo en diferentes tiempos, a pesar del cambio, conciernen a la identidad numérica, a la mismidad, mientras que la pregunta acerca de qué es lo nuclear en la autoconcepción de una persona, y por tanto, qué sería necesario preservar para que siga siendo la misma, concierne a la identidad narrativa.

Teniendo esto en cuenta, la posibilidad de una mejora que cambiara ciertas características del individuo, no afectaría a la identidad numérica, según DeGrazia, pues, en su sentido biológico, los cambios mentales de una persona no generarían otro organismo humano, sino el mismo. Más cuestionable es su afirmación de que, en su sentido psicológico, no se perdería la continuidad, en la medida en que la persona mejorada mantendría el recuerdo de quién era antes de la intervención. Según DeGrazia, el criterio de identidad como persistencia de una y la misma «vida mental» no se vería afectado, porque existirían conexiones psicológicas a lo largo del tiempo (por ejemplo, recuerdos de experiencias previas) o continuación de capacidades mentales, aunque éstas hayan sido mejoradas o modificadas en sus rasgos. No obstante, es posible pensar en modificaciones que afecten a la memoria (por ejemplo, eliminación de recuerdos dolorosos o traumáticos), en cuyo caso sí se podría producir una alteración de esa continuidad psicológica. 
Según DeGrazia, el error común, al no diferenciar estos dos tipos de identidad, es considerar que las mejoras en las características mentales pueden afectar la identidad de la persona en su conjunto, haciendo que sea otra y distinta de la anterior. Sin embargo, hay continuidad, al menos parcial, por la persistencia del organismo. El cambio se daría en cuanto a la identidad narrativa, y puede suponer una clara modificación de la biografía y la historia de un individuo. Pero, además, las intervenciones de mejora afectan la identidad narrativa en la medida en que influyen en la autoconcepción que el sujeto tiene de sí mismo. Alguien que adquiere nuevas capacidades, posiblemente se percibe a sí mismo de modo diferente y esto, sin duda, cambiar su modo de ser y afrontar su relación con el mundo.

Así, la crítica a la mejora insiste en la posibilidad de cambiar algunos aspectos nucleares de la identidad narrativa, de modo que el resultado sea una persona diferente. Es lo que plantea, por ejemplo, el President's Council on Bioethics. Pero esto exige determinar cuáles son esos aspectos nucleares, que definen la identidad, y que, o bien son específicos de cada sujeto, o de modo más general, son comunes a todos los individuos y, por tanto, equivaldrían a definir una naturaleza humana dada. Teniendo en cuenta que nos situamos dentro del terreno de la identidad narrativa, y no de la identidad numérica, hablar de una «esencia» humana resulta, cuando menos complejo. Sólo sería posible hablar de unas capacidades básicas que se modulan de modo diferente en cada individuo (por ejemplo, pensar, proyectar, comunicarse, etc.), dando como resultado un núcleo de rasgos que el propio sujeto considera básicos y definitorios de su persona y modo de ser (por ejemplo, alguien considerará que su capacidad de comunicación lo define y caracteriza, por ser éste un factor determinante en su biografía, sin el cual no podría entenderse ni ser él mismo o ella misma).

Con todo, el problema sigue abierto, pues la pregunta acerca de la bondad de una modificación que pretende mejorar estos rasgos no se puede responder de modo simplificador afirmando que ese núcleo de identidad es inviolable. De hecho, las modificaciones que todos experimentamos a lo largo de nuestro tiempo vital, y que configuran nuestra biografía, son en ocasiones casuales e inesperadas (por ejemplo, un accidente que deje secuelas físicas o psíquicas en una persona), pero también, en otros casos, buscadas deliberadamente (por ejemplo, alguien que se realice algunos cambios quirúrgicos en su cuerpo, para sentirse mejor y más seguro). Por supuesto, la valoración que se pueda hacer acerca de la seriedad o frivolidad de las razones para el cambio, no afecta a la valoración moral sobre su corrección, en la medida en que fuera voluntario y libremente elegido, y salvando las situaciones en que se pudiera detectar una alteración en la interpretación de la realidad, susceptible de ser abordada desde otra perspectiva (por ejemplo, que la elección de una cirugía transformadora fuera fruto de un evento traumático que hubiera generado una depresión en la persona).

Por tanto, que las personas elijan cambios que alguien pueda considerar absurdos, no es un argumento sólido para afirmar que la mejora pueda ser incorrecta moralmente. El problema se sitúa en el rechazo a una modificación de rasgos, considerados nucleares, que parecerían inviolables por su posibilidad de hacer perder la identidad de las personas, de hacer perder la misma humanidad.

Resulta evidente que definir estos rasgos resulta complejo, quizá imposible, y no es nuestro objetivo aquí, pero sí es necesario subrayar que, sean cuales sean, y aun suponiendo que pudiéramos acordar universalmente cuáles son, no son resultado exclusivo de la biología, no están determinados de modo absoluto por lo orgánico, sino que son el resultado de una interacción entre la naturaleza y el medio, entre lo biológico y lo 
cultural. Y por ello, insistir en la objeción a la modificación biológica puede ser un planteamiento parcial y una visión reduccionista del problema.

\section{LA IDEA DE UNA NATURALEZA HUMANA}

Los debates filosóficos propiciados por la neurociencia retoman en buena medida viejas discusiones. La posibilidad de realizar cambios en los seres humanos nos conduce, como se ha visto, a una pregunta acerca de ese núcleo que nos define como seres humanos y, por ello, se plantea, una vez más, la cuestión acerca de la existencia de una naturaleza humana.

Uno de los autores que ha abordado esta cuestión desde la ciencia actual es S. Pinker, quien afirma que existen diferencias innatas de comportamiento que resultan significativas entre los individuos. Este tipo de planteamientos ha reabierto un viejo debate relativo a la influencia de lo biológico-genético y lo ambiental-cultural en la configuración de los sujetos. Es la clásica distinción entra naturaleza y cultura, que vuelve a resurgir al enfatizarse los aspectos neurofisiológicos y genéticos del ser humano y considerarlos determinantes.

Según Pinker, el miedo a afirmar una naturaleza humana, con raíz en la genética, responde a cuatro temores básicos: en primer lugar, la desigualdad, ya que si las personas tuvieran, por naturaleza, facultades mentales diferentes, esto significaría una mejor dotación para ciertas actividades, lo cual podría dar lugar a discriminaciones o a una nueva forma de eugenesia. En segundo lugar, la imperfección, pues si la gente tiene ciertos sentimientos de modo innato, todo afán socio-político por crear un mundo más justo es una pérdida de tiempo. El cambio social sólo puede tener lugar si hay espacio para la transformación. En tercer lugar, el determinismo, es decir, la imposibilidad de atribuir responsabilidad a los agentes, pues ellos estarían siempre actuando conforme al patrón que marca su cerebro, sus genes o su evolución. En último lugar, el nihilismo, en tanto que si los motivos y los valores humanos son productos de la fisiología cerebral, forzados por la propia evolución, en realidad no existirían, tan sólo serían resultados explicables biológicamente.

En su opinión, todos estos miedos obedecen a concepciones erróneas y no se siguen necesariamente de la afirmación de una naturaleza humana. Por ello, considera que es compatible la afirmación de la libertad, de la toma de decisiones o del perfeccionamiento por medio de factores ambientales, aun asumiendo la existencia de una naturaleza dependiente de factores genéticos. Por ello critica tres afirmaciones frecuentes, que responden a ideas bastante clásicas: en nuestro mundo contemporáneo se habría instalado, según su diagnóstico, una convicción acerca de que la mente es una tabla rasa, de modo que no existen capacidades o temperamentos innatos, sino que todos son generados por el aprendizaje, la cultura y la sociedad. También, al afirmar esta condición, el ser humano sería bueno por naturaleza, el mito del buen salvaje que no tiene maldad inherente, sino generada por una corrupción externa propiciada por la sociedad. Y, finalmente, en la medida en que lo más importante de nosotros mismos es de alguna manera independiente de nuestra biología, nuestras posibilidades de experiencias y decisiones no pueden explicarse por razones fisiológicas ni evolutivas. Estas son las ideas que se ven comprometidas por los datos de las ciencias actuales, especialmente la genética y la neurofisiología. No obstante, la evidencia empírica se interpreta como una amenaza y, por ello, se combate en nombre de la defensa del ser humano. 
Pinker no tiene reparos en afirmar, a partir de los datos científicos, que existen diferencias biológicas - genéticas, neurológicas, etc.- entre los individuos, y que éstas son determinantes. En este sentido, los seres humanos no serían tablas rasas, sino que dispondrían de una serie de posibilidades o limitaciones innatas, que, no obstante, pueden ser, al menos parcialmente, modificadas. Enfatizar estos elementos frente a la fuerza de las explicaciones socioculturales no es, en su opinión, incompatible con la defensa de los más vulnerables, con la lucha por la igualdad, o con la búsqueda de la justicia. Por ejemplo, en relación a las diferencias entre varones y mujeres, Pinker subraya la importancia capital que tiene distinguir entre la proposición moral de que las personas no deben ser discriminadas por motivo de sexo, que él considera el núcleo del feminismo, y la proposición empírica de que hombres y mujeres son biológicamente indistinguibles. Para él, resulta evidente que son dos cosas diferentes, y que la distinción entre sexos no obsta a la lucha contra la discriminación, sino que, antes bien, considera que es esencial, precisamente para proteger ese núcleo del feminismo.

Su compromiso sociopolítico puede ser correcto, pero en el ámbito de la explicación de lo humano se le ha criticado a Pinker —al enfatizar demasiado el aspecto biológico-, por incurrir en ese tipo de reduccionismo que resulta tan frecuente en nuestros días, al pretender que las ciencias serán capaces de ofrecer una explicación completa del ser humano.

Esta cuestión —expuesta aquí de un modo muy resumido-, la idea de una naturaleza humana, está sin duda en la línea de las preocupaciones de otros pensadores que también han tenido en cuenta los datos de la ciencia de su época, para llegar a conclusiones interesantes. Así, por ejemplo, X. Zubiri asume que el ser humano parece irreductible a su naturaleza, pero que sin duda es naturaleza, pues su condición física y biológica son inexcusables y condicionan o posibilitan su mismo modo de ser. Pero al mismo tiempo, algo de razón tenía J. Ortega y Gasset al afirmar que el ser humano tiene historia y que, por tanto, es algo más o diferente, propio de las personas que están en un espacio construido, propio, habitado y posibilitante que es el mundo.

El ser humano, según Zubiri, se encuentra en una situación radicalmente distinta con respecto al resto de los seres vivos, puesto que se encuentra arraigado en su naturaleza y conjugándola con su libertad. La implantación en la realidad forma una unión indisoluble con la libertad que el ser humano va haciendo, por apropiación, conformando de este modo su vida.

Además, como animal de realidades, el ser humano tiene que realizar el modo de realidad que le es propio: el ser persona. Esa peculiaridad es la que le permite que su modo de ser real sea la autoposesión, es decir, estar sobre sí, ser suyo, y esto es lo que le confiere su personeidad, su ser persona. La forma de realidad humana, la personeidad, adquiere después modulaciones concretas que son su personalidad. Cuando hablamos de persona, por tanto, entendemos por tal la unidad concreta de la personeidad según la personalidad. Esto quiere decir que hay un cierto elemento "constructivo» en la configuración de la personalidad, dependiente en parte de las posibilidades biológicas que ese sujeto concreto tiene, y en parte de las posibilidades ambientales, temporales, históricas y culturales que se le abren en su mundo. Por eso, dice Zubiri «el hombre tiene naturaleza e historia; y en el marco de su naturaleza, el hombre inscribe su existencia personal. De manera que una persona determinada es lo que en su historia y en su vida le pertenece; porque «no todo lo que pasa en mí o conmigo es mío».

Puede interpretarse que la dimensión de personalidad abre ese espacio histórico y cultural, sin el cual la vida humana no sería realmente humana. El ser humano es agente y autor de su propia vida, constructor de su biografía. Y esa vida que la persona 
ejecuta también está condicionada por una determinada época, un determinado contexto socio-cultural, unas determinadas peculiaridades individuales, etc., lo que conforma todo un contexto que ya le viene dado a la hora de ejecutar sus acciones.

El ser humano se encuentra en un espacio de posibilidades, abierto a la realidad misma por la inteligencia. Esta capacidad es la que permite que las acciones ejecutadas lo sean en vista a la propia realidad del sujeto en tanto que realidad. Es decir, el ser humano se "va haciendo" en su fluir en la realidad. Y las acciones realizadas van configurando una figura del yo. La conciencia así no es tan sólo una transición entre estados de cosas, como si sólo fuera un espectador de lo que ocurre, sino que proyecta la propia realidad. El recorrido de la vida humana alcanza su unidad interna completándose y configurándose en la realidad, pues cada acción revierte sobre la realidad del mismo ser humano. Por eso Zubiri, al enfatizar este aspecto constructivo, fluyente e inacabado, se apoya en la realidad física y en el ámbito o campo de posibilidades dadas, pero explica al ser humano como una interacción que deviene, cambia, se constituye y da como resultado una nueva realidad.

Probablemente, considerar que el ser humano puede describirse por su naturaleza, es decir por su condición genética, por sus rasgos biológicos — lo que configura su personeidad-, y por su apropiación de posibilidades, la forma de personalidad que va adquiriendo, que es dinámica, abierta, cambiante, e inconclusa, es una visión compleja y acorde con los datos científicos. De esta manera, los avances en la neurociencia actual le proporcionarían a Zubiri nuevas bases en las que sustentar su descripción de la naturaleza humana, pero su planteamiento podría recibir críticas similares a las vertidas contra Pinker, pues enfatizar el arraigo biológico del ser humano es precisamente lo que hace este autor.

Le salva a Zubiri el no haber prescindido de la situación del ser humano como realidad que tiene un mundo, como modo propio de ser. Sin embargo, a la altura de nuestro tiempo, parecería necesario quizá ampliar la descripción, para dar cabida al impacto de lo cultural como auténtico elemento configurador de la identidad. Que los aprendizajes recibidos son capaces de modificar físicamente nuestro cerebro - generando, por ejemplo, nuevas conexiones neuronales - es algo ahora bien sabido, que sin duda llevaría a afirmar la interacción entre lo biológico y lo cultural. Que existen diferencias cerebrales correlativas a las diferencias de costumbres, de género, de lenguaje, etc. también permitiría matizar algunas cuestiones. Que nuestras capacidades tecnológicas tienden a permitir la modificación cerebral y con ello lograr efectos como la mejora de la memoria o la atención, supone también un ámbito de reflexión que obligaría a revisar y completar buena parte de las afirmaciones pues, si los recuerdos forman parte de la identidad de la persona, al quedar como el sustrato de las acciones pasadas y las experiencias vividas, poder intervenir en la memoria, además de una esperanza para los enfermos de Alzheimer, puede constituir una inquietante forma de reconfiguración de la personalidad sobre la que es preciso reflexionar.

\section{NeURociencia CUltural}

Según lo visto, a menos que se insista en que sólo se puede hablar de naturaleza humana desde una perspectiva formal, enfatizando la existencia de unas capacidades que son posibilidades que pueden desarrollarse o no, el debate acaba por dar la razón a quienes buscan un sustrato material para todo lo que somos y, con los datos de la neurociencia, ese sustrato es básicamente el cerebro y sus procesos. Pero, como se ha indicado, 
conviene completar y matizar esta perspectiva con una dimensión más ambiental y cultural. Todos los seres humanos están sujetos a interacciones ambientales, culturales y sociales. Y las diferencias en esas experiencias determinan también distintos estilos cognitivos. Cada vez más, los estudios en neurociencia sugieren que esas diferencias ligadas a la cultura tienen una importancia capital. Así, por ejemplo, algunos estudios muestran cómo los occidentales tienden a procesar los datos con una perspectiva más analítica, mientras que los asiáticos tienden a prestar más atención a la información contextual.

Este es el campo que viene desarrollando la llamada «neurociencia cultural», investigando las variaciones culturales en los procesos psicológicos, neurales y genómicos, como modo de comprender la relación bidireccional que existe entre estos procesos y sus propiedades emergentes. Chiao la describe como «un campo interdisciplinar que tiende un puente entre la psicología cultural, las neurociencias y la neurogenética para explicar cómo los procesos neurobiológicos, como la expresión genética y la función cerebral, dan lugar a valores, prácticas y creencias culturales, además de cómo la cultura moldea los procesos neurobiológicos a escala macro y micro temporal». Esto es, la neurociencia cultural trata de analizar cómo los rasgos culturales modulan y configuran la neurobiología y el comportamiento, y en sentido inverso, cómo los mecanismos neurobiológicos facilitan la emergencia y transmisión de los rasgos culturales.

La importancia de estos estudios sobre las influencias de lo cultural y lo genético en la función cerebral descansa en la evidencia creciente de que la cultura influye en los procesos psicológicos y en el comportamiento. En la medida en que el comportamiento es resultado de la actividad neuronal, la variación cultural en el comportamiento es el resultado de la variación cultural en los mecanismos neurales subyacentes.

Los estudios realizados se han centrado principalmente en cómo estas variaciones culturales repercuten en cómo las personas se perciben a sí mismas en relación a los otros (individualismo frente a colectivismo), el reconocimiento de las emociones, la empatía, o la teoría de la mente.

Los hallazgos de la neurociencia cultural tienen importantes implicaciones: por un lado revelan la naturaleza sensible a las diferencias culturales del cerebro humano, lo que nos permite comprender que este órgano, a nivel biológico, puede ser modulado y configurado por los contextos socioculturales. Estos contextos tienen que ver con espacios de interacción social, en los que puede darse la cooperación o la lucha, y en los que el cerebro humano podrá desarrollar procesos neurocognitivos que ayuden al individuo a funcionar y adaptarse a un ambiente sociocultural específico. Esto puede ayudarnos a pensar sobre los conflictos y malentendidos que surgen entre personas procedentes de diferentes grupos culturales. Y nos obliga a volver sobre la cuestión de la universalidad y la peculiaridad cultural en los mecanismos neuronales que subyacen a la cognición y el comportamiento humano.

La influencia bidireccional de lo cultural y lo biológico reabre también el viejo debate de lo natural y lo cultural, de «lo nacido» $\mathrm{y}$ «lo hecho», para establecer un enlace entre ambos elementos. El cerebro se muestra como un órgano relacional que es capaz de vincular el mundo biológico del organismo con el mundo social y cultural del ambiente. En medio de una fuerte influencia de los planteamientos más biologicistas y materialistas, que parecen querer reducir todo lo que somos a un sistema causa-efecto aparentemente determinado, esta perspectiva viene a subrayar cómo muchos aspectos de nuestros patrones de pensamiento y comportamiento, o más aún, nuestra misma biología, son configurados por el ambiente en el que nos desarrollamos. Y este ambiente, donde están las personas, sus ideas, sus valores, y sus acciones, son tan reales como cualquier otro elemento del mundo físico. 
Y, por otro lado, al permitirnos entender las diferencias culturales en los comportamientos humanos, nos obliga a repensar cuánto y cómo podemos determinar las acciones de los individuos, en la medida en que la cognición y el comportamiento se adhieren a un cierto ambiente cultural, resultando en una suerte de «imprinting» cultural del cerebro. Sin duda, esto tiene importantes consecuencias para la educación, y de hecho, una de las cuestiones que suscita la neurociencia cultural es qué clase de experiencias, durante el desarrollo, pueden facilitar la capacidad de los cerebros de los individuos para encajar dentro de una cultura específica y para interactuar con personas de otras culturas diferentes. Este nexo entre la naturaleza y la cultura supone también asumir que no somos receptores pasivos, sino que constantemente estamos creando condiciones nuevas para nuestro pensamiento y nuestras acciones.

\section{LA MEJORA MORAL, UN RETO DIFÍCIL DE NEGAR}

Regresando ahora al tema de la mejora de las capacidades por medio de neurofármacos, la investigación en neurociencia cultural también puede aportar luz, por ejemplo, a la determinación de cómo ciertas sustancias bioquímicas o neurotransmisores podrían ser sensibles a las experiencias culturales. Esto abre una puerta a la posibilidad de mejorar rasgos de los individuos que sean socialmente valiosos. Es lo que se ha dado en llamar «mejora moral», esto es, la mejora de rasgos y comportamientos considerados promotores de valores fundamentales, que tradicionalmente hemos cultivado a través de la cultura y la educación, como la justicia o la solidaridad.

Autores como Savulescu consideran que, dada la peligrosa tendencia de los seres humanos a la autodestrucción, sería justificable buscar una mejora moral que disminuyera la maldad, contribuyera al desarrollo de actitudes más benevolentes, más amables, más altruistas, etc. Si, como apuntan los resultados de las investigaciones neurocientíficas, nuestras disposiciones morales están basadas en nuestra biología, sería razonable modificar nuestros comportamientos a través de un cambio biológico, que podría ser tan sencillo como la introducción de determinadas sustancias químicas en el agua que bebemos. Y esto, como en otras ocasiones, se plantea no sólo como una posibilidad aceptable, sino como un imperativo moral: si podemos mejorar la vida y la convivencia humana, tenemos obligación de hacerlo.

Así las cosas, si tenemos en nuestras manos la posibilidad de hacer que el mundo sea más humano, que la justicia se vea desarrollada y completada por la solidaridad, sin que otros intereses se antepongan ante el florecimiento de las personas. Si estamos desarrollando fármacos que, una vez probada su seguridad, puedan ofrecernos la posibilidad de ser más comunicativos, más abiertos, tener mayor atención y memoria, pensar mejor y más rápido, eliminar recuerdos que nos disturban o nos duelen, estar más alegres y plenos de energía. Si todo esto nos permite ser más y desarrollar al máximo nuestras posibilidades, hacer que podamos elegir con mayor libertad, dando lo mejor de nosotros mismos. Si todo esto es posible, y el ejemplo de los neurofármacos apunta en esta dirección, ¿qué es lo que resulta tan perturbador y alarmante?

La respuesta, tras el breve análisis realizado, se sitúa en la necesidad de enfatizar el aspecto cultural y, por tanto, la educación. Por supuesto que no podemos desdeñar ni prescindir del arraigo biológico del que somos deudores. Y posiblemente no sea descabellado introducir algunas modificaciones, pues el afán de mejora es lícito, y si aceptamos las modificaciones ambientales, también deberíamos ser capaces de diseñar racionalmente, con prudencia y responsabilidad, cómo introducir algunas modificaciones 
biológicas. Pero, precisamente por esa doble interacción entre lo biológico y lo cultural, de la que somos resultado, conviene evitar la ingenuidad de pensar que las técnicas de mejora cerebral harán todo sencillo y evidente. Difícilmente podremos crear un mundo más justo o podremos ser mejores personas, si no tomamos en consideración que los seres humanos somos un conjunto articulado y dinámico de elementos biológicos y elementos culturales, que construimos nuestras vidas en un espacio de interacción y convivencia en el que vamos generando nuevas posibilidades continuamente - como ésta, de la mejora, que requiere seguir pensando a fondo-, y en el que dotamos de sentido a nuestra identidad y nuestra existencia narrativamente, haciendo nuestra historia.

Universidad Complutense de Madrid

Lydia Feito Grande

Lydiafeito@ucm.es

[Artículo aprobado para publicación en diciembre de 2014]. 